\title{
Studies on the In Vitro Trypanocidal Effect of the Extracts of Some Selected Medicinal Plants in Sokoto State, Nigeria
}

\author{
${ }^{* 1}$ A.Y. Bala, ${ }^{1}$ T. Adamu, ${ }^{1}$ U. Abubakar, ${ }^{2}$ M.J. Ladan and M.G. Abubakar \\ ${ }^{1}$ Department of Biological Sciences Usmanu Danfodiyo University, Sokoto \\ ${ }^{2}$ Department of Biochemistry Usmanu Danfodiyo University, Sokoto \\ [*Correspondence Address: aminubala2001@ yahoo.com; $\boldsymbol{\nabla}+\mathbf{2 3 4 ( 0 ) 8 0 3 5 9 8 9 8 2 4 ]}$
}

\begin{abstract}
The in vitro trypanocidal activity of aqueous extracts of some selected medicinal plants used by local herdsmen in the treatment of various animal diseases in Sokoto State, Nigeria was conducted. Trypanosoma brucei brucei were cultured using 96 well micro titer plate and maintained at $37^{\circ} \mathrm{C}$. About $20-25$ parasites per microscope field were dosed with 1,2 and $4 \mathrm{mg} / \mathrm{ml}$ of aqueous extracts of the plants and a control group without extracts. After 5 minutes incubation in Eppendorf tubes maintained at $37^{\circ} \mathrm{C}$, the parasites survived more than four (4) hours in the absence of extract/Berenil. At $4 \mathrm{mg} / \mathrm{ml}$ of the extracts Of Terminalia catappa, Waltheria indica, Cucurbita pepo, Entada abyssinica and Ximenia Americana, complete cessation of motility of $T$. brucei brucei within 60 minutes was observed. However, at $2 \mathrm{mg} / \mathrm{ml}$ of Waltheria indica, trypanosome motility after 20 minutes was stopped but Terminalia catappa, and Ximenia americana were found to reduce trypanosome motility at 35 and 55 minutes respectively. Only Waltheria indica reduced trypanosome motility within 25 minutes at $1 \mathrm{mg} / \mathrm{ml}$ concentration. Berenil, the standard drug, caused cessation of trypanosomal motility within 60 minutes even at $1 \mathrm{mg} / \mathrm{ml}$. From the results Waltheria indica was the most effective among the extracts when compared with Berenil, and may be a potential source of compounds with trypanocidal activity.

KEYWORDS: in vitro, trypanocidal activity, medicinal plants, sokoto, Nigeria
\end{abstract}

\section{INTRODUCTION}

Human Trypanosomiasis is endemic in Africa and South America. In Africa, the disease known as Human African Trypanosomiasis (HAT) or sleeping sickness, is caused by Trypanosoma brucei gambiense (chronic form) or T. brucei rhodesiense (acute form), whereas the American Trypanosomiasis known as Chagas' disease, is caused by T. cruzi. Sleeping sickness and Chagas' disease are both transmitted by vectors (Segura et al., 1999). Human African Trypanosomiasis is transmitted during blood meals by tsetse flies, while the American Trypanosomiasis is transmitted by reduviid bugs. In addition to human infectious trypanosomes, a variety of other species cause animal Trypanosomiasis with a wide geographic distribution. Nagana is caused by $T$. brucei brucei in Africa and affects cattle; $T$. congolense and $T$. vivax infect domestic and small animals on many continents (Hoare, 1972). T. brucei brucei and T. congolense are similar to T. brucei gambiense and T. brucei rhodesiense, in that they are transmitted through tsetse fly bites, while $T$. evansi is spread by mechanical transmission of infected blood through haematophagus insects such as tabanid flies. T. evansi is closely related to other Trypanozoon species, including T. brucei gambiense and $T$. brucei rhodesiense, at the generic level.

Trypanosomiasis has recently become resurgent in Africa (WHO, 1998). WHO reports that 66 million people in 36 African countries are afflicted and Animal Trypanosomiasis causes the death of 3 million cattle each year (WHO, 1998, Truc, 2003, Chreten and Smoak, 2005).

Chemotherapy remains the principal means of control (FAO, 1998) and possibly eradication of the disease (Ogbunugafor et al., 2007, Ekanem and Oluwatosin, 2008). Current treatment of African Trypanosomiasis is problematic especially for patients with late stage disease and nervous system involvement. The available drugs cannot be taken orally and are generally toxic (TDR, 2005). Berenil is widely used for the treatment of the early stage animal Trypanosomiasis but is highly toxic (TDR, 2005), producing brain damage, quivering, and restlessness in treated animals, besides being excreted quickly (Kellner et al., 1985).

There are only two drugs known to be effective against the late stage of the disease, Difloromethyl ornithine (DFMO, eflornithine $®)$ and Melarsprol@. DFMO can only cure $T$. 
brucei gambiense infections. Furthermore, because of the lengthy infusion schedules, it can only be administered in a hospital setting (Fijolek et al, 2007); it remains expensive to manufacturers (TDR, 2005) and is no longer available in the market (Agbedahunsi et al, 2006). Melarsprol, an arsenical derivative, has serious side effects such as fatal encephalophathy in as high as $10 \%$ of the cases. Furthermore, there is an increasing resistance to Melarsprol reaching almost $30 \%$ in Central Africa (Fijolek et al., 2007).

Because of the highly variable nature of the trypanosome glycoprotein coat, all attempts to develop an efficient vaccine have met with little success (Fijolek et al., 2007). These limitations in chemotherapy of sleeping sickness are a cause for major concern because the disease is 100\% fatal (Agbedahunsi et al., 2006).

Several reports on the evaluation of different chemicals/drugs for trypanocidal activity have appeared, just as are interesting reports on the antiT.1 effects of plant extracts and plant derivatives (Atawodi et al, 2003). Some of these reports have indeed shown that at least some of these plants possess trypanocidal activity. Since herbal treatment for various diseases in Africa is still wide spread, an ethnobotanical approach in collaboration with traditional healers may prove to be a rich source of drug discovery. Moreover, Sokoto State, being a semi - arid region, is included in the tsetse free belt of the country and therefore left out in the current fight against Trypanosomiasis. But the zone is equally endowed with medicinal plants that may probably have the potential to cure the disease. In addition, Ajagbonna et al. (2003) and Bala et al. (2005) have shown Garlic and Cassia occidentalis, to produce a life prolonging effect on trypanosome - infected rats when treated with the plants.

Therefore, as a follow up to this, we present in this study, report on systematic in vitro assessment of aqueous extracts of some medicinal plants, found in Sokoto State, for their trypanocidal activity using $T$. brucei brucei as test organisms. It is hoped that results from the study will be of great importance in the current global effort to find alternative, cheap and effective products for the treatment of trypanosomiasis.

\section{MATERIALS AND METHODS Collection and Identification of the Plants}

The choice of plants used in this study, was based on a structured oral interview conducted amongst the local herdsmen in different parts of Sokoto State. The herdsmen were asked the plants they use in treating animals diseases with debilitating effects. Some of these diseases are usually characterized by inappetence, lethargy, weakness, loss of weight, emaciation, pica, rough hair coat, lameness, abortion in females, infertility in male and female animals, salivation, lacrimation, etc which usually culminate in death if untreated.

The plants were identified at the Botany Unit of the Department of Biological Sciences, Usmanu Danfodiyo University, Sokoto. A voucher specimen for each plant was deposited in the herbarium of the Department (Table 1). 


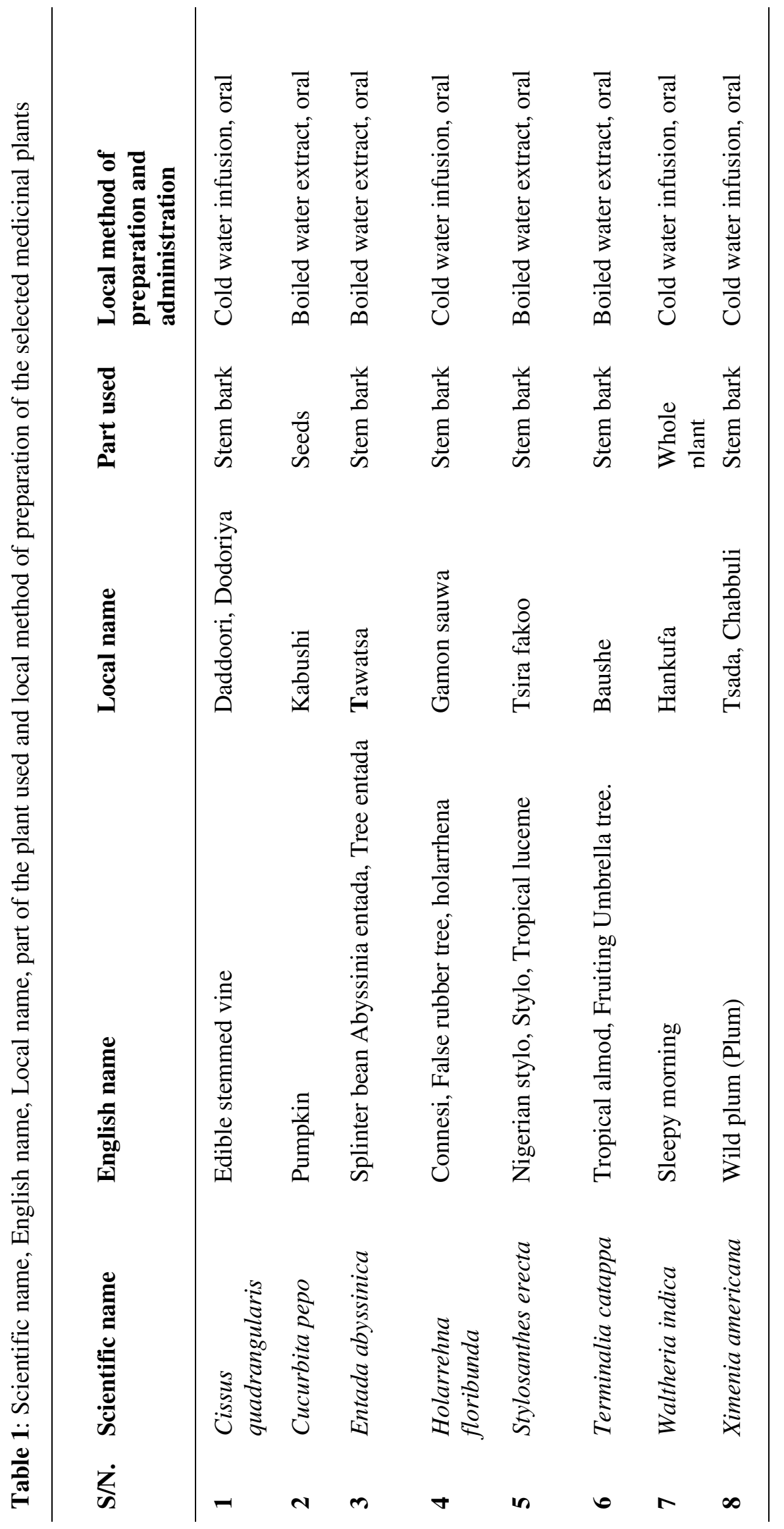


EXTRACTION OF PLANTS MATERIALS

Whole part of Waltheria indica, seeds of Cucurbita pepo and stem barks of Cissus quadrangularis, Holarrehna floribunda, Terminalia catappa, Entada abyssinica, Ximenia americana and Stylosanthes erecta were cut into pieces, air-dried (under shade or in open air in the laboratory to avoid denaturing the active components) at room temperature and pulverized using mortar and pestle to coarse powder.

A $100 \mathrm{~g}$ powder of each plant was extracted with $500 \mathrm{ml}$ of distilled water. It was then manually shaken vigorously for six hours (alternatively shaken for ten minutes and resting for 15 minutes). It was then allowed to stand for the next 18 hours, shaken again for ten minutes and filtered using size 1 Whatmann filter paper. The volume of each filtrate was noted and placed in an electric drier and evaporated slowly at $45^{\circ} \mathrm{C}$ as described by Muyibi et al., (2000).

\section{TEST ORGANISMS}

T. brucei brucei were obtained from stabilates maintained at the Nigerian Institute of Trypanosomiasis and Onchocerciasis Research (NITOR) Vom, Plateau State. The parasites were maintained in the laboratory by continuous passage in rats until required. Passage was carried out when parasitaemia reached between $16-32$ parasites per field (usually $3-5$ days post infection). In passaging, $1 \times 10^{3}$ parasites in $0.1-0.2 \mathrm{ml}$ blood/PBS solution was injected intraperitoneally into naive rats acclimatized under laboratory condition for one week.

\section{DETERMINATION OF PARASITAEMIA}

Parasitaemia was monitored in blood obtained from the tail, pre-sterilized with methylated spirit. The number of parasites was determined microscopically at X 400 magnification using the "Rapid Matching" method of Herbert and Lumsden (1976). Briefly, the method involves microscopic counting of parasites per field in pure blood or blood appropriately diluted with buffered phosphate saline (PBS, $\mathrm{pH}$ 7.2). Logarithmic values of these counts obtained by matching with the table of Herbert and Lumsden (1976) is converted to antilog to provide absolute number of trypanosomes per $\mathrm{ml}$ of blood.

\section{IN VITRO TRYPANOCIDAL ACTIVITY}

Assessment of in vitro trypanocidal activity was performed in triplicates in 96 well micro titer plates (Atawodi et al, 2003), but with slight modification. $0.5 \mathrm{~g}$ of each extract was dissolved in $25 \mathrm{ml}$ distilled water to obtain $20 \mathrm{mg} / \mathrm{ml}$ extract. Concentrations of 10 and $5 \mathrm{mg} / \mathrm{ml}$ were also formed, giving three different concentrations for each extract. The 20,10 and $5 \mathrm{mg} / \mathrm{ml}$ concentrations of each plant extract were prepared in triplicates.

Twenty microlitres $(20 \mu \mathrm{l})$ of blood containing about $20-25$ parasites per field obtained as described above, were mixed with $5 \mu 1$ of each extract to produce effective test concentrations of $4 \mathrm{mg} / \mathrm{ml}, 2 \mathrm{mg} / \mathrm{ml}$ and $1 \mathrm{mg} / \mathrm{ml}$ respectively. To ensure that the effect monitored was that of the fraction alone, two sets of control were set up. First Diminazene aceturate (Berenil - a standard drug) was used as positive control and then blood suspended in normal saline was used as a second (negative) control. Berenil was prepared in the same concentration as the extracts $(445 \mathrm{mg}$ Diminazene aceturate $+555 \mathrm{mg}$ Antipyrine, Eagle Chemical Company Ltd, Ikeja, Nigeria)

Each of the test mixtures was incubated for 5 minutes in closed Eppendorf tubes maintained at $37^{\circ} \mathrm{C}$. Two(2) $\mu \mathrm{l}$ of test mixture was placed on separate microscope slides and covered with a cover slip and the parasites observed every 5 minutes for a total duration of sixty (60) minutes. Cessation or drop in motility of the parasites in extract-treated blood compared to that of the parasite-loaded control blood without extract was taken as a measure of trypanocidal activity (Atawodi et al, 2003). 


\section{RESULTS}

The percentage yield of the various plants extracts is shown in Table 2. Five plants, namely Cucurbita pepo, Entada abyssinica, Terminalia catappa, Waltheria indica and Ximenia americana caused complete cessation of motility of $T$. brucei brucei within 60 minutes at $4 \mathrm{mg} / \mathrm{ml}$ extract concentration (Table 3). Waltheria indica caused the cessation within the first 10 minutes, Terminalia catappa and Ximenia americana caused cessation within 55 minutes, while Cucurbita pepo and Entada abyssinica stopped trypanosome motility within 60 minutes. Two plants, Stylosanthes erecta and Holarrehna floribunda caused slight reduction in motility of $T$. brucei brucei within
50 and 60 minutes respectively. The extracts of Cissus quadrangularis had no effect on the parasites at this concentration.

Table 2: Percentage Yields of Extracts

\begin{tabular}{clc}
\hline S/NO & \multicolumn{1}{c}{ Plant } & Yield (\%) \\
\hline 1. & Cissus quadrangularis & 27.24 \\
2. & Cucurbita pepo & 22.60 \\
3. & Entada abyssinica & 16.80 \\
4. & Holarrehna floribunda & 21.18 \\
5. & Stylosanthes erecta & 23.72 \\
6. & Terminalia catappa & 26.53 \\
7. & Waltheria indica & 21.75 \\
8. & Ximenia Americana & 19.36 \\
\hline
\end{tabular}

Table 3: Effect of Different Concentrations of the Aqueous Extracts of Some Medicinal Plants on Motility of T. brucei brucei

\begin{tabular}{cccc}
\hline & \multicolumn{2}{c}{ Time (Min) after which motility ceased, reduced drastically, or } \\
Plant & 4 & 2 & 1 \\
\hline Cissus quadrangularis & - & - & - \\
Cucurbita pepo & $30^{\text {SRM }}$ & $40^{\text {SRM }}$ & - \\
& $40^{* *}$ & $60^{* *}$ & \\
Entada abyssinica & $60^{*}$ & & - \\
& $25^{\text {SRM }}$ & - & - \\
Holarrehna floribunda & $45^{* *}$ & & - \\
Stylosanthes erecta & $60^{*}$ & - & $55^{\text {SRM }}$ \\
Terminalia catappa & $50^{\text {SRM }}$ & - & \\
& $10^{\text {SRM }}$ & $25^{\text {SRM }}$ & $15^{\text {SRM }}$ \\
Waltheria indica & $20^{* *}$ & $35^{* *}$ & $25^{* *}$ \\
& $55^{*}$ & $5^{\text {ARM }}$ & $55^{*}$ \\
Ximenia americana & $5^{* *}$ & $15^{* *}$ & - \\
Diminazene aceturate & $10^{*}$ & $20^{*}$ & \\
& $25^{\text {SRM }}$ & $45^{\text {SRM }}$ & $55^{* *}$ \\
\hline
\end{tabular}

- = No effect on motility after 60 minutes, $\quad$ SRM $=$ slightly reduced motility, ${ }^{*}=$ ceased/stopped motility,

$* *$ reduced motility drastically.

At $2 \mathrm{mg} / \mathrm{ml}$ Waltheria indica caused stoppage in trypanosome motility after 20 minutes, Terminalia catappa and Ximenia americana drastically reduced trypanosome motility after 35 and 55 minutes respectively, while at this concentration, the other plant extracts had no effect on the parasites.
At $1 \mathrm{mg} / \mathrm{ml}$ concentration, Waltheria indica drastically reduced trypanosome motility after 25 minutes, while all other plant extracts had no such effect on the trypanosome parasites.

Diminazene aceturate (Berenil) caused cessation of $T .1$ motility within 60 minutes even at the lowest concentration tested $(1 \mathrm{mg} / \mathrm{ml})$. 
The results also showed that after 5 minutes incubation in Eppendorf tubes maintained at $37^{\circ} \mathrm{C}$, the trypanosome parasites survived for about 4 hours when no extract was present.

From the results Waltheria indica was the most effective plant extract at all concentrations tested. The result also indicated that the extract of Waltheria indica was the most effective at $4 \mathrm{mg} / \mathrm{ml}$ concentration because it stopped trypanosome motility within 10 minutes. At same concentration Berenil caused cessation of movement after 5 minutes.

\section{DISCUSSION}

Results of this study showed that the extracts of some of the plants (Terminalia catappa, Waltheria indica, Cucubita pepo, Entada abyssinica and Ximenia americana) had strong trypanocidal activity in vitro, while the extracts of Stylosanthes erecta and Holarrhena floribunda had moderate trypanocidal activity, with extract of Cissus quadrangularis showing no in vitro effect.

That some of the plants showed promising trypanocidal effect is not surprising, since earlier reports (Asuzu and Chineme, 1990; Owolabi et al, 1990; Nok et al, 1993; Freiburghaus et al., 1996, 1997, 1998; Bala et al, 2005; Agbedahunsi et al, 2006) have clearly indicated that plants of different families could possess potent trypanocidal activity. In fact, natural products with trypanocidal activity and belonging to a variety of phytochemical classes have been identified (Hopp et al, 1976; Sepulveda - Boza and Cassels, 1996; Oliver Bever, 1986).

The reported in vivo trypanocidal activity of the extract of Terminalia spp at $150 \mathrm{mg} / \mathrm{kg}$ in mice experimentally infected with trypanosome parasites in Mali (Bizimana et al, 2006), is confirmed by this in vitro assay.

In an earlier report (Bacchi, 2003), the leaf extract of Holarrhena floribunda was shown to possess in vivo trypanocidal activity in trypanosome infected mice. The present report of lack of in vitro trypanocidal activity of the stem bark extract emphasises the need to study all parts of a plant before any generalisation is made on the plant therapeutic potential.

Moreover, a plant with high in vitro trypanocidal activity may have no in vivo activity and vice versa. This is because there are peculiarities in the metabolic disposition of the chemical constituents of plants. Therefore plants found to be active in this study must be tested in vivo before a definite statement can be made on their trypanocidal potentials.

It is difficult to speculate the mechanism by which the plants extracts' exhibit their trypanocidal action. However accumulated evidence (Sepulveda - Boza and Cassels, 1996) suggest that many natural products exhibit their trypanocidal activity by virtue of their interference with the redox balance of the parasites acting either on the respiratory chain or on the cellular defences against oxidative stress. This is because natural products possess structures capable of generating radicals that may cause peroxidative damage to trypanothione reductase that is very sensitive to alterations in redox balance. It is also known that some agents act by binding with the kinetoplast DNA of the parasite.

The findings in this study clearly reaffirm the in vitro system employed in this investigation as a fast and reliable system for in vitro screening of plants and other materials for trypanocidal activity.

From this brief study, it seems clear that local herdsmen do indeed possess a noteworthy knowledge of medicinal plants which should be acknowledged and considered in the search for novel compounds for the treatment of parasitic diseases. Further studies including in vivo assays for the determination of efficacy and toxicity are recommended.

\section{REFERENCES}

Agbedahunsi, J.M., Anao, I., Adewunmi, C.O. and Croft, S.L. (2006). Trypanocidal Properties of Terminalia ivorensis A. Chev. (COMBRETACEAE). Afr. J. Traditional. Complem. Altern. Med., 3(2): $51-56$.

Ajagbonna, O.P., Mikahil, H.G. and Muhammad, B.Y. (2003). Effect of aqueous extract of Allium sativum (Garlic) on haematological and biochemical parameters in rabbits infected with T. brucei. Proceedings of the $28^{\text {th }}$ Annual Conference of the Nigerian Society for Animal Production, 28:95 - 97.

Asuzu, I.U. and Chineme, C.N. (1990). Effects of Morinda lucida leaf extracts on $T$. brucei brucei infection in mice. $J$. Ethnoparmacol. 30: 307- 313. 
Atawodi, S.E., Bulus, T., Ibrahim, S., Ameh, D.A., Nok, A.J., Mamman, M. and Galadima, M. (2003). In vitro Trypanocidal effect of methanolic extract of some Nigerian Savannah plants. Afr. J. of Biotechnol. 2 (9): 317-321.

Bacchi, C.J. (2003). Drug development and conservation of Biodiversity in West and Central Africa. WRAIR, 3: $1-20$.

Bala, A.Y., Adamu, T., Abubakar, U. and Ladan, M.J. (2005): The efficacy of the leaf extract of Cassia occidentalis in the treatment of $T$. brucei brucei infection in albino rats. Bulletin of the SAN 26: 224233.

Bizimana, N., Tietjen, L.I., Zessin, K., Diallo, D., Djibril, C., Melzig, M.F. and Clausen, H. (2006). Evaluation of Medicinal plants from Mali for their in vivo trypanocidal activity. J. Ethnopharmacol. 103(3): 350 -356 .

Chretien, J.P.L. and Smoak, B.L. (2005). African Trypanosomiasis: Changing Epidemiology and Consequenses. Curr. Infect. Dis. Rep., 7: $54-60$.

Ekanem, T.J. and Oluwatosin, K.Y. (2008). Some Biochemical and Haematological effects of Black seed (Nigella sativa) oil on T. brucei infected rats. Afr. J. Biotech. 7 (2): 153 - 157.

Fijolek, A., Hofer, A. and Thelander, L. (2007). Expression, Purification, Characterization and in vivo Targeting of Trypanosome CTP synthetase for Treatment of African Sleeping Sickness. J. Biol. Chem., 282(16): $11858-11865$.

Food and Agricultural Organisation (FAO) (1998). Drug management and parasite resistance In Bovine Trypanosomiasis: 3 10.

Freiburghaus, F., Kaminsky, R., Nkuna, M.H.N., Brun, R. (1996). Evaluation of African medicinal plants for their in vitro trypanocidal activity. J. Ethnopharmacol. 55: $1-11$.

Freiburghaus, F., Jonker S. A, Nkuna, M. H. N., Mwasunbi, L. B and Brun, R. (1997). In vitro trypanocidal activity of some rare Tanzanian medicinal plants. Acta Tropical., 67: $181-185$.

Freiburghaus, F., Steck, A., Pfander, H., Brun, $\mathrm{R}$ (1998). Bioassay guided isolation of a diastereoisomer of kolavenol from Entada absyssinica active on T. brucei rhodense. J. Ethnopharmacol. 61: 179 - 183.
Herbert, W.J and Lumsden, W.H. (1976). T. brucei: a rapid matching method for estimating the host parasiteamia. Experim. Parasitol. 40: 427-31

Hoare, C.A (1972). The Trypanosomes of Mammals: A Zoological Monograph, Oxford Blackwell Scientific Publications. Hoechst AG.

Hopp, K.H., Cunningham, L.V., Brome,1 M.C., Schermester, L.J. and Wahba, K.S.K. (1976). In vitro antiT.1 activity of certain alkaloids against $T$. lewisi. Lloydia, 39: $375-377$.

Joshi, P.P, Shegokar, V.R., Powar, R.M., Herder, S., Katti, R., Salkar, H.R., Dani, V.S., Bhargava, A., Jannin, J. and Truc, P. (2005). Human Trypanosomiasis caused by $T$. evensi in India: The first case report. Am. J. Trop. Med. and Hyg., 73 (3): 491 - 495.

Kaminsky, F., Nkuna, M. H. N. and Brun, R. (1996). Evaluation of African Medicinal Plants for their invitro Trypanocidal Activity. J. Ethnopharmacol., 55: 1 - 11 .

Kellner, H. M., Eckert, H. G. and Volz, M. H. (1985). Studies in cattle of the anti-T.1 drug Diminazene aceturate (Berenil). Trop. Med.Parasitol., 36: 199 - 204.

Muyibi, S. A., Olorode, B. R., Onyeyili, P. A., Osunkwo, U. A., Mohammed, B. Y. and Ajagbonna, O. P. (2000). Haematological and Histopathological Changes of Senna occidentalis leaf extract in rats. Nig. J.Nat. Prod. and Med., 4: 48 - 52.

Nok, A. J., Esievo, K. A. N., Arowosafe, S., Onyenekwe, P. C., Gimba, C. E. and Kagbu, J. A. (1993): In vitro activity of leave extracts against $T$. brucei brucei. J. of Clin. Biochem. Nutr., 15: 113 - 118.

Ogbunagafor, H. A., Okochi, V. I., Okpuzor, J., Adebayo, T. and Esue, S. (2007). Mitragyna ciliate and its trypanocidal activity. African Journal of Biotechnology, 6 (20): 2310 - 2313.

Oliver - Bever, B. (1986). Medicinal plants in tropical West Africa. Cambridge University press, Cambridge, MA: 16 42.

Owolabi, O. A., Makanga, B., Thomas, E. W., Molyneux, D. H. and Oliver, R. W. (1990). Trypanocidal potentials of Africa woody plants. In vitro trials of Khaya grandifolioli seed extracts. Journal of Ethnopharmacology, 30: 227 - 231. 
Segura, E. L., Sosa Estani, S., Esquivel, M., Gomez, A. and Salomon, O. D. (1999). Control of the transmission of T. cruzi in Argentina. Medicina, 59: 91 - 96.

Sepulveda-Boza, S. and Cassels, B. K (1996). Plant metabolites active against $T$. cruzi. Planta Medica, 62: 98-105.

Tropical Disease Research (TDR) (2005). Making Health Research Work for Poor People, Human African Trypanosomiasis. Seventeenth Programme Report, 2003 2005.

Truc, P. (2003). About Trypanosome brucei gambiense. The causative form for human
African Trypanosomiasis: Some findings and proposals. African Journal of Biotechnology, 2(12): 657 - 661.

Truc, P., Jamonneau, V., N'Guessan, P., N'Dri, L., Diallo, P. B. and Cuny, G.(1998). T. brucei spp. and $T$. congolense: Mixed human infection in Cot d'Ivoire. Trans Royal Society of Tropical Medicine and Hygiene, 92: 537 - 538.

WHO (1998). African Trypanosomiasis (Sleeping sickness) Control, Communicable Disease Surveillance and Response WHO/OMS: Technical Report Series 881: 1-36, Geneva. 